\title{
REFLEXÃO SOBRE APRENDIZAGEM MATEMÁtICA NA PERSPECTIVA HISTÓRICO-CULTURAL
}

\section{ARTIGO ORIGINAL}

SCHWANTES, Vilson '1, XAVIER, Márcio Pizzete 2, KRACKE, Elisa ${ }^{3}$, GRAUNKE, Carla Kuhn ${ }^{4}$, GONÇALVES JÚNIOR, Affonso Celso 5, SCHWANTES, Eloísa Bernardete Finkler ${ }^{6}$

SCHWANTES, Vilson. Et al. Reflexão sobre aprendizagem matemática na perspectiva Histórico-Cultural. Revista Científica Multidisciplinar Núcleo do

\footnotetext{
${ }^{1}$ Mestrado em Educação nas Ciências - Matemática. UNIJUI: Universidade Regional do Noroeste do Estado do Rio Grande do Sul, RS. Especialização: Ensino de Ciências. FAFIG: Faculdade Estadual de Filosofia, Ciências e Letras de Guarapuava. Graduação em Matemática. UPF(Universidade de Passo Fundo), RS. Graduação em Ciências $1^{\circ}$ Grau. FACIP: Faculdade de Ciências e Pedagogia de Lages, SC.

2 Graduanda em Agronomia - UNIOESTE - Universidade Estadual do Oeste do Paraná. Graduanda de Administração - Unip - Universidade Paulista.

3 Mestrando em Desenvolvimento Rural Sustentável, UNIOESTE: Universidade Estadual do Oeste do Paraná. Especialista em Matemática e Física, UNIPAR. Graduação em Matemática com ênfase em Física, UNIPAR.

${ }^{4}$ Especialista Em Educação Matemática E Especialista Em Física Educacional.

${ }^{5}$ Pós-Doutor Em Ciências Ambientais.
}

${ }^{6}$ Especialização em Ensino de Ciências Exatas - Matemática, Física e Química. UNIOESTE - Universidade Estadual do Oeste do Paraná.

RC: 84456

Disponível em: https://www.nucleodoconhecimento.com.br/comunicacao/marketing-nosdeliverys 
Conhecimento. Ano 06, Ed. 05, Vol. 02, pp. 106-131. Maio de 2021. ISSN: 2448-0959, Link de acesso: https://www.nucleodoconhecimento.com.br/educacao/historicocultural, DOI: 10.32749/nucleodoconhecimento.com.br/educacao/historico-cultural

\section{RESUMO}

A pesquisa bibliográfica busca na perspectiva histórico-cultural o referencial teórico para refletir sobre o processo ensino-aprendizagem da matemática, dada a importância da linguagem, produção e internalização de significados sobre ela, no trabalho com situações-problema. A dinâmica do processo de produção e internalização de significados para a matemática se dá, na pesquisa, a partir do livro A Construção do Pensamento e da Linguagem de Vygotsky (2001). Considera a linguagem como um conjunto de símbolos construídos socialmente e legitimados pela cultura e pelas práticas do cotidiano. Enfatiza a relevância das interações entre os seres humanos para o aprendizado escolar e o papel da linguagem no processo dialógico dessas interações mediadas pelo uso de signos. Na reflexão, a investigação busca conhecer como ocorre a formação do pensamento teórico-matemático, e a aprendizagem na perspectiva histórico-cultural. Acredita que ao trabalhar dialogicamente situações-problema sentidos são produzidos no processo de internalização a partir da posse da linguagem significada, facilitando a aprendizagem.

Palavras-chave: Linguagem, Pensamento Algébrico, Produção de Significado, Signos, Aprendizagem Matemática.

\section{INTRODUÇÃO}

\subsection{A PERSPECTIVA DA TEORIA HISTÓRICO-CULTURAL DE VYGOTSKY PARA A EDUCAÇÃO.}

As pesquisas realizadas por Vygotsky enfatizam que a aprendizagem ocorre principalmente a partir de processos sociais. Em suas pesquisas o autor ressalta a

RC: 84456

Disponível em: https://www.nucleodoconhecimento.com.br/comunicacao/marketing-nosdeliverys 
importância do desenvolvimento do indivíduo e da espécie humana, como resultado de um processo sócio-histórico. Em seus estudos, esse autor procurou analisar o reflexo do mundo exterior no mundo interior dos indivíduos a partir da interação destes com a realidade circundante. Acredita que a origem das mudanças que continuam ocorrendo na espécie humana, ao longo de seu desenvolvimento, perpassa as interações sociais que por sua vez se refletem na história individual.

Essa abordagem busca, em síntese, enquadrar numa mesma perspectiva o homem enquanto corpo e mente e enquanto ser biológico e social, participante da evolução da espécie humana e de seu processo de constituição histórica. Vygotsky (2001) demonstra que no homem o desenvolvimento histórico se sobrepõe ao biológico. Assim, considera que o desenvolvimento humano é de natureza cultural, mas isso não significa para o autor a negação da realidade biológica. O biológico e o cultural, embora constituam naturezas diferentes, são duas dimensões constitutivas e interdependentes de uma mesma e única história individual.

Os experimentos de Vygotsky, realizados durante a primeira metade do século $X X$, revolucionam a cada dia as áreas da psicologia e da educação. Em suas pesquisas ele e seus colaboradores trabalharam com situações-problema, na crença de transformar a sociedade pelo conhecimento, através de um processo social-histórico de mediação entre os sujeitos pela linguagem. Defendem através de seus escritos a ideia de popularizar o conhecimento, com ênfase no papel do professor e através do uso da linguagem como mediadora do processo educativo para a formação e qualificação de recursos humanos.

Chamado pelos estudiosos de sociointeracionista, Vygotsky foi durante vários anos de sua vida, como tantos outros intelectuais, perseguido e proibido de divulgar suas ideias. Em seu livro: A Construção do Pensamento e da Linguagem (2001) parte da concepção de que no ser humano tudo é construído, nada é inato. Nessa obra, mostra experimentalmente o quanto o meio social é assimilado e incorporado pelo sujeito que interage com e num mundo histórico em permanente (re) construção.

RC: 84456

Disponível em: https://www.nucleodoconhecimento.com.br/comunicacao/marketing-nosdeliverys 
Em sua teoria, Vygotsky (2001) pressupõe que o ser humano busca em todas as suas ações produzir o novo, não aceitando a mesmice e o espontaneísmo. Nessa visão, o apropriamento dos conhecimentos científicos ocorre através de um processo educativo organizado, planejado e executado intencionalmente pela escola. A adoção de uma prática pedagógica de caráter interativo-dialógica possibilita a compreensão dos significados produzidos nas interlocuções. Compete ao professor negociar com a classe o transacionamento dos significados histórico-socialmente construídos, para que sejam sistematizados e incorporados ao conhecimento formal compreendendose, agora melhor, ambos os saberes.

Nessa linha teórica, a educação assume um caráter dialético e democrático, mediada por uma linguagem que permite o pensamento e os aspectos psicológicos do sujeito. Pensamento e conhecimento são (re)construídos e se desenvolvem ao longo do desenvolvimento humano. O pensamento humano é visto, nessa perspectiva, como um reflexo da linguagem, perdendo o cérebro sua capacidade evolutiva, somente a partir do momento em que inicia seu processo de degeneração biológica.

Em relação à educação, Vygotsky (2001) enfatiza mais a cultura do ser humano do que a herança biológica de seu desenvolvimento cognitivo. Seus escritos sugerem um ensinar e um aprender sem dogmatismos, valorizando a história contextualizada. A construção do conceito é vista como um processo em desenvolvimento contínuo, reflexo de interações dialógicas, evitando-se, nessa perspectiva, um ensino tradicional, verbalista e unidirecional.

Em situações de aprendizagem, o professor usa a linguagem para ensinar e aprender, e o aluno também aprende por meio da linguagem. Assim, em suas modalidades oral e escrita - a linguagem é o elemento central do desenvolvimento do pensamento e da consciência humana (FARIAS e BORTOLANZA, 2015).

De acordo com Vygotsky (2001), o sujeito se constitui na relação com o outro. Na sala de aula, numa situação de ensino, tanto o professor quanto os alunos são vistos como

RC: 84456

Disponível em: https://www.nucleodoconhecimento.com.br/comunicacao/marketing-nosdeliverys 
sujeitos que se constituem através de uma aprendizagem intersubjetiva. Assim, entendemos que uma prática pedagógica fundamentada nas ideias de Vygotsky pode oferecer a possibilidade de constituir, na escola, sujeitos não 'assujeitados', potencialmente dialógicos e reflexivos.

Trabalhar com a educação de crianças, adolescentes, jovens e adultos, segundo a perspectiva histórico-cultural, exige do coletivo escolar a organização de um projeto de educação que privilegie, segundo (LINS, 1999, p. 92), a "[...] ampliação dos significados que são legitimados na rua, e não na substituição da rua pela escola". Para a concretização de um projeto de educação com esta perspectiva, o autor apresenta uma postura educacional como alternativa, a qual enuncia:

Não sei como você é; preciso saber. Não sei também onde você está (sei apenas que está em algum lugar); preciso saber onde você está para que eu possa ir até lá falar com você e para que possamos nos entender, e negociar um projeto no qual eu gostaria que estivesse presente à perspectiva de você ir a lugares novos (LINS, 1999, p. 85).

É preciso construir um espaço comunicativo através do qual seja possível compartilhar os saberes que o aluno traz consigo da vivência e experiência pessoal e a partir disso produzir significados que dêem legitimidade a esses saberes, possibilitando impactos na vida dos alunos. As ações pedagógicas desencadeadas na sala de aula, a partir desta perspectiva, podem possibilitar uma melhor compreensão desses saberes. Tais saberes podem proporcionar ao aluno uma continuidade na assimilação de informações, alcançando profundidade nos conhecimentos sistematizados.

Em seu livro (eletrônico), Novas tecnologias e mediação pedagógica (2015), Moran ressalta a importância de um trabalho docente motivador, que trabalhe os conteúdos de matemática contextualizados, para não gerar um desestímulo pela disciplina.

O modelo de passar conteúdo e cobrar sua devolução é insuficiente. Com tanta informação disponível, o importante para educar é encontrar a ponte motivadora para que o aluno desperte e saia do estado passivo, de espectador. Aprender hoje é buscar, comparar,

RC: 84456

Disponível em: https://www.nucleodoconhecimento.com.br/comunicacao/marketing-nosdeliverys 
pesquisar, produzir, comunicar. Só a aprendizagem viva e motivadora ajuda a progredir (MORAN, 2015, p.34).

As ideias de Vygotsky (2001) procuram analisar os processos característicos do funcionamento mental e da consciência, incorporam saberes das diversidades culturais e das dinâmicas das práticas sociais, nas quais estes saberes se constituem. A obra do autor caracteriza-se por valorizar, no ato educativo, as práticas que envolvem relações de ensino cotidianas, formais e informais.

Por compreender que o desenvolvimento do ser humano é produzido a partir do contexto cultural, Vygotsky (2001) e as suas ideias vêm conquistando cada vez mais a simpatia de educadores de várias áreas do conhecimento. De acordo com as palavras de Paulo Bezerra, tradutor do livro mencionado anteriormente, no enfoque histórico-cultural dá-se ênfase ao papel desempenhado pelos signos "[...] como elemento fundamental de construção da relação do homem com o mundo [...]", quer seja para nomear ou para comunicar ideias. Concebe assim, importância para os conceitos, elaborados a partir da interação do sujeito com os aspectos socioculturais presentes no meio onde o indivíduo vive (VYGOTSKY, 2001, p. 12).

Para o pensador, o aluno integra a sociedade civil organizada a partir do seu nascimento. Assume papéis fundamentais na construção de seu desenvolvimento, participa da história e da cultura de sua comunidade. Aprende as primeiras lições de vida com seus familiares próximos e distantes. Perpassam também, na construção de seu desenvolvimento, as experiências socialmente vividas, os hábitos, as atitudes, os valores e a linguagem de todos que interagem com ele, nos âmbitos familiar e social e nos diversos grupos de iguais. Influencia, de forma análoga, o acesso aos meios de comunicação escrita, falada e virtual. O ambiente social onde o aluno está inserido proporciona, em última instância, condições de modelação do pensamento e da linguagem servindo como motivador e encorajador para a busca do novo.

Contudo, não se pode ser ingênuo, no sentido de entender esse processo como um determinismo histórico e cultural. Precisa-se ter ciência de que o aluno não absorve RC: 84456

Disponível em: https://www.nucleodoconhecimento.com.br/comunicacao/marketing-nosdeliverys 
passivamente determinados comportamentos, valores, hábitos e a própria linguagem. Ele, de forma ativa, participa da construção de sua cultura e de sua história, modificando-se e provocando transformações nele e em todos que com ele vivem e interagem.

Uma prática pedagógica que enfatiza a aprendizagem, o papel que o meio social exerce no processo de desenvolvimento do ser humano é, segundo Vygotsky (2001), uma prática em que tanto a linguagem quanto os signos são considerados construções sociais e se desenvolvem pelas interações ao longo da vida dos indivíduos. São, portanto, ideias que pressupõem uma escola e uma educação de 'novo tipo', com espaços de felicidade, liberdade, dialogicidade e interatividade.

O aluno é entendido, segundo essa linha teórica, como um sujeito social e histórico, um ser que sente, sonha, deseja, pensa, age, se expressa e se relaciona em um contexto de tempo e espaço determinado histórica e socialmente. Ao mesmo tempo ele determina esse contexto pelas suas interações em casa, na rua, na escola, onde reconstrói uma nova realidade e se reconstrói a partir dessas relações em cada situação vivenciada.

Os estudos de Vygotsky (2001) nos fazem refletir sobre o papel que a linguagem assume como fundadora de uma nova relação do gênero humano para consigo mesmo e para com o mundo, o que traz novas perspectivas para o processo ensinoaprendizagem.

RC: 84456

Disponível em: https://www.nucleodoconhecimento.com.br/comunicacao/marketing-nosdeliverys 


\section{DESENVOLVIMENTO}

\subsection{A PERSPECTIVA HISTÓRICO-CULTURAL NA EDUCAÇÃO MATEMÁTICA}

Entendemos, em nossa reflexão, a matemática como uma ciência em permanente construção e interação com os outros saberes. Uma práxis educativa em que o sujeito se constitui pela educação.

Pela significação da linguagem, que permite o pensamento, Vygotsky (2001) apresenta um entendimento das relações estabelecidas entre sujeitos no processo ensino-aprendizagem. Essa perspectiva já influenciou várias disciplinas, porém, aqui nos interessa refletir sobre a dimensão cognitiva da aprendizagem de modo geral e da educação matemática de forma particular.

De acordo com Vygotsky (2001), o sujeito desempenha um papel ativo-interativo nas relações que são estabelecidas a partir de um processo que se origina nas funções sociais e comunicativas do ser humano. Esse processo caminha do plano social relações interpessoais - para o plano individual interno - relações intrapessoais. As relações intrapessoais servem às funções de planejamento e à solução de problemas. O sujeito ativo-interativo constitui conhecimentos e se constitui a partir dessas relações inter e intrapessoais, produzindo significados nas interações sociais. Segundo (FONTANA, 1996, p. 11), Vygotsky afirma que:

[...] é no curso de suas relações sociais (atividade interpessoal) que os indivíduos produzem, se apropriam (de) e transformam as diferentes atividades práticas e simbólicas em circulação na sociedade em que vivem, e as internalizam como modos de ação/elaboração 'próprios' (atividade intrapessoal), constituindo-se como sujeitos (grifo da autora).

São as trocas dialógicas entre os seres humanos, tendo como objeto o conhecimento, que na produção e compreensão da palavra possibilitam o estabelecimento de uma

RC: 84456

Disponível em: https://www.nucleodoconhecimento.com.br/comunicacao/marketing-nosdeliverys 
relação entre pensamento e linguagem que favorece a produção de significados sobre a palavra e, por conseguinte, a generalização. Nesta dimensão, a produção do conhecimento matemático perpassa pela via dialógica, na qual o aluno passa a estabelecer relações entre o saber matemático vivenciado fora do âmbito escolar e o construído historicamente, sistematizado através do ensino formal.

Pelas relações interpessoais entre alunos, entre aluno e professor, entre aluno e comunidade estabelece-se uma possibilidade de reconstrução do mosaico da realidade educacional vigente, no qual o conteúdo matemático, além de trabalhado fragmentadamente, está posto como algo cristalizado. Na perspectiva de Vygotsky, o ser humano está se desenvolvendo sempre, num contínuo amadurecimento de suas funções psicológicas e, juntamente com ele, tudo o que o rodeia.

No que tange ao ensino de matemática, acreditamos que o ensino da disciplina também precisa acompanhar as transformações sociais contínuas. A forma de ensinar e aprender, necessita incorporar uma prática pedagógica favorecida pelas relações interpessoais, que devem estar, nessa dimensão, em primeiro plano.

Em suma, a matemática vista como uma ciência produzida pela humanidade. Exercendo uma função de destaque nos currículos escolares, ajudando as culturas a conhecer, compreender e interpretar as diferentes formas de matematizar de que se utiliza.

Esse conhecimento produzido pela humanidade é estruturado em códigos para explicar e manejar a realidade circundante. $O$ trabalho matemático, mesmo o escolar, não pode esquecer de fazer sua leitura crítica do mundo a partir da realidade vivida.

De acordo com Vygotsky (2001), o aluno, desde seu nascimento, tem seus gestos e atitudes significadas pelo outro. Nessa relação, a linguagem torna-se instrumento de intermediação do conhecimento, constituindo o desenvolvimento psicológico do 
mesmo. Pela aprendizagem, nas relações que estabelece com o outro, esse aluno elabora o conhecimento que possibilita o seu desenvolvimento mental.

Para o autor, o professor desempenha um papel essencial para que ocorra a aprendizagem. Tendo os signos como mediadores do processo ensinoaprendizagem, o professor participa como coadjuvante e possibilita a interação entre o conhecimento espontâneo e o saber sistematizado pela comunidade científica.

Assumir a matemática, na perspectiva de Vygotsky é assumi-la como algo construído histórico-socialmente. Devemos compreendê-la como participantes e integrantes de um mundo social, que contém regras e normas de raciocínio e entender que sua aprendizagem requer não só a aquisição de conceitos, mas também de valores vivenciados a partir das práticas sociais.

Acreditamos que os estudos de Vygotsky podem servir de aporte para um olhar redimensionado sobre a práxis matemática no ensino. O desafio é, a partir do uso natural da linguagem cotidiana sobre situações-problema, identificar significados produzidos na interlocução estabelecida entre professor-aluno, aluno-aluno, numa tentativa de, pela internalização desses significados, que pela linguagem são significados, constituir-se o pensamento matemático.

Na perspectiva enunciada, o professor deixa de ser o condutor principal do processo ensino-aprendizagem, assume o papel de introdutor dos sistemas conceituais, transacionando os significados destes e, pelo viés da linguagem, propicia o desenvolvimento do pensamento matemático. Neste aspecto cabe ao docente facilitar o encontro do aluno para consigo mesmo e com os demais. Nas dificuldades, podese permitir a significação do contexto, oferecendo aos alunos pequenas pistas, uma nova pergunta, um novo pensamento pertinente, que favoreça e permita o transacionamento de significados. 
De acordo com Vygotsky (2001), a linguagem exerce num primeiro plano a função comunicativa, porém, seu papel fundamental é o de constituir o pensamento e a consciência. Através dela somos capacitados a formular conjecturas, conceitos, generalizações de fatos da realidade e da matemática.

Nessa dinâmica, a linguagem, seja ela verbal, escrita, musical, geométrica, corporal, simbólica, ou outra qualquer, permite ao ser humano expressar um pensamento de forma geral. Sua utilização torna-se fundamental para a matemática e para a representação de ações do pensamento, como por exemplo, na representação de imagens, sons, palavras, sensações, sentimentos, ações, entre outros.

A possibilidade de constituição de um pensamento generalizante, fundamental na aprendizagem matemática propicia, nesta perspectiva, facilidade na comunicação de ideias matemáticas que perpassam $n$ situações vivenciadas no mundo. Para Vygotsky é a linguagem significada que nos permite estruturar as formas de pensamento. Nela e através dela marcamos nosso ingresso na cultura, constituindo-nos como sujeitos singulares. Comunicamos, explicamos e representamos a realidade de modo geral e expressamo-la matematicamente por meio de linguagem específica, através de signos.

A exploração dialógica de situações-problema, que trazem subjacentes, padrões numéricos, geométricos, dentre outros, pode possibilitar, pela linguagem e por meio das regularidades intrínsecas, a exploração de generalidades. A percepção dessas regularidades é favorecida pelo ato dialógico o qual desenvolve o pensamento matemático, permitindo a representação dos signos matemáticos. A produção de significados para os conceitos matemáticos, nas interações produzidas na ação pedagógica, segundo a perspectiva histórico-cultural, caracteriza-se como uma oportunidade docente ímpar de constituição e desenvolvimento do pensamento matemático. 


\subsection{A IMPORTÂNCIA DO PAPEL DA LINGUAGEM NO APRENDIZADO DA MATEMÁTICA ESCOLAR}

Enraizada no passado, a escola apresenta dificuldades em vislumbrar seu papel de criadora de espaços de felicidade e sucesso. Impõe, por isso, quase sempre, disciplina rígida, exigindo silêncio, memorização de conceitos e regras, sem muitas diferenças na forma como se processa a educação escolar dos adultos. Na fase escolar, para o aluno, tudo é movimento, diálogo, observação, manuseio. Segundo (VYGOTSKY, 1998, p. 131), "Numa criança em idade escolar, inicialmente a ação predomina sobre o significado [...]".

Para (FREITAS, 1995, p. 158), "[...] o sentido das coisas é dado ao homem pela linguagem. Na linguagem, no diálogo, na interação, estão o tempo todo o sujeito e o outro". Diante desse quadro, questiona-se: É possível obrigar os alunos a se apaixonarem, pela matemática, por exemplo, quando esta é ensinada de forma descontextualizada? Quando ela não se liga a sua vida diária? A quem cabe ensinar o aluno a se posicionar frente à complexidade do mundo vivido, estimulando a busca de soluções próprias para os desafios da vida em família e na sociedade? Um bom começo, segundo (LINS e GIMENEZ, 1997, p. 10) pode ser, "[...] partir do que é mais familiar [...]", de problemas da vivência do aluno, desenvolvendo o conhecimento de si próprio para chegar ao conhecimento do meio mais amplo.

Ferreira (2013), em sua pesquisa de mestrado realizada na educação básica, verificou que os conceitos de matemática adotados pelos professores com os alunos estão se resumindo basicamente em resoluções algébricas e aplicação de métodos de resoluções, com utilização de fórmulas, caracterizando uma aprendizagem mecânica e sem significado concreto e contextualizado para os discentes. Diante disso, urge a necessidade de um fazer pedagógico que possibilite a aprendizagem matemática a partir das experiências de vida dos alunos fora do âmbito escolar, respeitando o que é peculiar em cada comunidade.

$\mathrm{RC}: 84456$

Disponível em: https://www.nucleodoconhecimento.com.br/comunicacao/marketing-nosdeliverys 
Dessa maneira, é importante que prática pedagógica em sala de aula seja reorientada para o desenvolvimento da cidadania dos alunos. Nesse contexto, Pinheiro e Rosa (2016) argumentam que é importante que os:

(...) professores de matemática mergulhem na dinâmica cultural dos alunos e utilizem estratégias de ensino e aprendizagem que valorizem a dimensão cultural existente na sala de aula, para que se desenvolva uma educação matemática inclusiva que possa efetivamente contribuir para a transformação social (PINHEIRO e ROSA, 2016, p. 79).

$\mathrm{Na}$ escola o aluno aprende com facilidade um conteúdo matemático qualquer quando for capaz de lhe atribuir um significado. Daí a importância do ensino escolar não ignorar os conhecimentos e conceitos que circulam no contexto cultural onde os alunos vivem. O ser humano é sociocultural, estabelece relações com a realidade circundante e, pela sua capacidade reflexiva, reconstrói aprendizagens a partir de conhecimentos já existentes.

De acordo com (DUARTE, 1994), a forma como devemos ver e entender o mundo nos é ensinada pelos nossos semelhantes através da linguagem. Somos educados segundo o código lingüístico da comunidade onde estamos inseridos. Nesse contexto, a linguagem assume primeiramente sua função comunicativa e a sala de aula passa a ser ininterruptamente um espaço de diálogo, de debate, de aprendizagens recíprocas, de constituição do pensamento.

Nessa prática pedagógica, sair do tecnicismo, centrar o olhar na perspectiva de ligar o mundo da vida com o mundo escolar pode contribuir na minimização do processo de exclusão escolar. Como educadores às vezes ignoramos o conhecimento matemático produzido pelos diferentes grupos sociais, bem como os conhecimentos matemáticos trazidos pelo aluno desta convivência. Ter sensibilidade para perceber que o aluno aprende em casa as noções básicas de matemática, quer seja contando com o auxílio dos dedos, quer seja comparando objetos, analisando medidas de capacidade, relações de tempo e espaço, torna-se fundamental para o ato educativo.

RC: 84456

Disponível em: https://www.nucleodoconhecimento.com.br/comunicacao/marketing-nosdeliverys 
O caminho para o êxito do processo ensino-aprendizagem escolar está em partir desses conhecimentos básicos para sistematizá-los e aprofundá-los. Não se pode ignorar na escola a bagagem de conhecimentos socialmente construídos pelo aluno. Vale lembrar que em suas pesquisas (VYGOTSKY, 1998, p. 132) constatou que "[...] - comportamento humano passa a depender de operações baseadas em significações [...]".

A linguagem dá ao ser humano as condições necessárias para a sua existência. Por meio dela o homem se expressa, pode dizer o que quer e ser compreendido. A palavra torna-se caminho pelo qual podemos pensar e refletir sobre como o pensamento algébrico pode ser desenvolvido durante a vida escolar, permitindo-nos seu entendimento e compreensão.

Somos seres humanos pelo ato educativo, e pela linguagem significada constituímos nosso pensamento e consciência. Ela determina nossa socialização, expressa nossa forma de pensar, agir, falar, interpretar, enfim, determina nosso estilo de vida, nossa personalidade cultural segundo as normas da tradição da comunidade onde estamos inseridos. Por meio da linguagem incorporamos novos valores culturais, éticos, sociais e educacionais.

Ao aprender a usar a linguagem para planejar uma ação futura, a criança consegue ir além das experiências imediatas. Esta 'visão do futuro' (ausente nos animais) permite que as crianças realizem operações psicológicas bem mais complexas (passa a poder prever, comparar, deduzir etc.) (REGO, 1998, p. 66).

Segundo (DEMO, 1996), ter língua significa ter mundo, um mundo articulado na realização do ato comunicativo, pois a linguagem denota a base da comunicação, na condição vital de saber expressar-se, um dos fundamentos mais notáveis da cidadania. Ela "realiza o encontro entre o mundo moderno da comunicação, pervadido de tecnologia, e o mundo da vida, pervadido de cultura" (DEMO, 1996, p. $66)$.

RC: 84456

Disponível em: https://www.nucleodoconhecimento.com.br/comunicacao/marketing-nosdeliverys 
Pensamos que não basta a linguagem cumprir seu papel comunicativo, como propõe Demo, há que perpassar este âmbito e contribuir para a constituição do pensamento, conforme acredita Vygotsky. Neste cenário, também a matemática pode reassumir sua função de ampliar os significados matemáticos que são legítimos do aluno, ampliando a sua compreensão do mundo. Um trabalho educativo consistente incorpora os saberes oriundos da vida social, incentiva a educação permanente e a formação de um aluno-cidadão com competência para ocupar seu espaço, situandoo como sujeito participante de vanguarda da sociedade brasileira.

Para Vygotsky (2001), a linguagem é ferramenta básica na construção do conhecimento. Ela é instrumento simbólico básico do ser humano e age sobre o pensamento, modificando-o e possibilitando o desenvolvimento da estrutura das funções psicológicas superiores[7]. Para o autor a influência da linguagem e sua relação com o pensamento é tão decisiva na formação da consciência humana quanto são os instrumentos criados pelos homens para modificar e transformar as formas da vida humana. Ela age decisivamente na organização do raciocínio reestruturando diversas funções psicológicas, como a memória, a atenção e a formação de conceitos. Pela linguagem, somos capazes de criar o novo e de (re)interpretar o mundo sempre de forma renovada.

De todas as aptidões humanas é a linguagem a mais manifesta. Ela caracteriza a identificação do ser humano como ser racional. O ser humano fala e o faz sem saber exatamente como e porque, no entanto, é através da linguagem que ele se constitui como humano, faz a leitura da própria vida, da sua história de vida e de sua aprendizagem. Para Vygotsky (2001) é através dela que o homem consegue elaborar e desenvolver o pensamento de caráter generalizante. Ela é ponto de partida para qualquer ação educativa quer seja nas relações concretas estabelecidas nos grupos de iguais, quer seja a partir delas.

Ao estudar a linguagem se está, na realidade, tentando compreender melhor aquilo que nos é mais característico e, consequentemente, aprendendo mais sobre a nossa RC: 84456

Disponível em: https://www.nucleodoconhecimento.com.br/comunicacao/marketing-nosdeliverys 
condição humana. Segundo Freitas (1995), para Bakhtin não há realidade sem linguagem. Talvez esse seja o motivo pelo qual seu estudo é algo tão interessante e fascinante.

Segundo Vygotsky (2001), o ser humano não nasce pronto, tampouco é cópia do ambiente externo. O referencial histórico-cultural pressupõe que o homem produz linguagem e se produz na e pela linguagem. A evolução intelectual da espécie perpassa por evoluções permanentes e ininterruptas através de processos internos e influências que ocorrem no mundo social onde o sujeito está inserido. $O$ aprendizado essencial para o desenvolvimento do ser humano e de toda sua espécie é atribuído ao papel exercido pela linguagem na organização do pensamento.

Nessa perspectiva, a capacidade do uso da linguagem possibilita o aluno a posicionarse criticamente na sociedade, permite-Ihe a comunicação e a representação do pensamento. $O$ uso da linguagem é ação comunicativa implicada nas normas do contexto social que dão sentido e significação à linguagem expressa pelas palavras, o que modifica comportamentos e atitudes de crianças, jovens e adultos. Em tese, segundo Vygotsky (2001), a generalização e a abstração só são possíveis através do uso da linguagem.

A criança nasce num mundo que é por natureza simbólico. Os sujeitos usam significados para exercer controle sobre o ambiente circundante e sobre si próprios. Os pequenos constituem seu próprio sistema de significados pela interação com membros da sua cultura - mãe, pai, irmãos, amigos, professores, com os meios de comunicação e tecnológicos. Ao longo do processo de desenvolvimento humano, as pessoas vão abandonando as marcas externas e, aos poucos, passam a utilizar representações mentais em substituição às representações dessas marcas. Influenciado pelas interações sociais, o sujeito começa, paulatinamente, a imaginar, planejar, generalizar sua forma de pensar.

RC: 84456

Disponível em: https://www.nucleodoconhecimento.com.br/comunicacao/marketing-nosdeliverys 
Para Vygotsky (2001), quando um bebê estende a mão para pegar um objeto e o adulto o aproxima dele, o bebê está agindo por impulso, pois a ação está no objeto, em decorrência da cor, forma, entre outros atrativos que o objeto possa apresentar. Nesta fase o bebê ainda não separa pensamento de objeto, construindo somente mais tarde significados, conhecimentos, valores, num diálogo que estabelece com o adulto e com seu mundo de vida. Se no início a criança usa esta forma de linguagem difusamente, gradativamente passará a estabelecer elos entre sua ação difusa e a organizada pela outra pessoa.

Nesse processo sequencial, primeiramente a criança toma conhecimento das palavras pelas pessoas com as quais ela interage. Posteriormente, ao observar um novo objeto, ela indaga e quer saber o nome. Para (VYGOTSKY, 2001, p. 131) “[...] a criança necessita da palavra e procura ativamente assimilar o signo pertencente ao objeto, signo esse que the serve para nomear e comunicar". Pela linguagem significamos e estabelecemos relações com o mundo e nos relacionamos com a realidade pelo entendimento obtido pela palavra.

É através da linguagem que o aluno alavanca todo o processo de desenvolvimento cognitivo, tornando-se ela aos poucos um instrumento do pensamento. Na fase escolar, a aprendizagem ocorre de forma organizada e intencional, induz para a zona de desenvolvimento proximal, ajudando a criança a avançar do nível de desenvolvimento real para uma área de potencialidades desenvolvidas na mediação por meio de signos e aprimorada através do ato dialógico reflexivo com o outro.

Um trabalho pedagógico nessa perspectiva requer comunicabilidade entre os atores. Requer professores que saibam dar voz a seus alunos, possibilitando o surgimento de conhecimentos e valores construídos e reconstruídos pela ação dialética. Sem dúvida, uma prática pedagógica que enfatiza um agir com o outro, incorporando o conhecimento do outro. Para (FREITAS, 1995, p. 98), "Através da linguagem a criança entra em contato com o conhecimento humano e adquire conceitos sobre o mundo 
que a rodeia, apropriando-se da experiência acumulada pelo gênero humano no decurso da história social".

A importância dada à linguagem, nessa abordagem, não significa uma volta ao ensino tradicional, no sentido de se valorizar a transmissão de conteúdos monologicamente, tampouco no seu sentido linear, em que o professor ensina e os alunos aprendem. Paulo Freire já mostrou a falência desta visão estreita, que manipula e configura um agir sobre o outro. Vygotsky leva em consideração a importância da mediação social, isto é, enfatiza que entre o sujeito e o objeto existe um outro elemento, o signo. Este por sua vez, é o meio através do qual, dialogicamente, ocorre a constituição do pensamento.

Em suas pesquisas, Vygotsky tomou por base o desenvolvimento do indivíduo como resultado de um processo através do qual transforma-se de biológico em sóciohistórico. Nessa caminhada a cultura é fundamental para a efetiva constituição da natureza humana. A linguagem e a aprendizagem assumem papel decisivo e contínuo ao longo do desenvolvimento do sujeito. Os conhecimentos são apropriados pela interação que o ser humano estabelece de forma mediada através dos signos com o mundo.

A prática pedagógica da matemática, nessa perspectiva, tem como meta o desenvolvimento das potencialidades individuais dos sujeitos a partir do seu contexto sócio-histórico. É fundamental trabalhar partindo do que o aluno sabe e não a partir de suas deficiências como ocorre na maioria de nossas escolas. O professor tem seu papel valorizado e o aluno que puder aprender com o auxílio de outras pessoas, terá seu desenvolvimento, segundo Vygotsky (2001), mais acelerado em comparação a outro que tiver que fazê-lo sozinho.

$\mathrm{Na}$ perspectiva sociocultural o aluno é considerado participante de um processo coletivo de construção e reconstrução de saberes pela interlocução. A linguagem se

RC: 84456

Disponível em: https://www.nucleodoconhecimento.com.br/comunicacao/marketing-nosdeliverys 
constitui o meio privilegiado para obtê-los. Ao se apropriar dela o aluno se capacita a olhar reflexiva e criticamente a realidade a sua volta, podendo ou não transformá-la.

\subsection{A APRENDIZAGEM MATEMÁtICA NA PERSPECTIVA HISTÓRICO-CULTURAL}

Muitas vezes a escola adota uma postura que exige comportamentos e rendimentos iguais de alunos que são diferentes. Acentua em sua prática as deficiências, ao invés de desenvolver as potencialidades individuais. Para Selbach são:

[...] aulas que se fundamentam apenas no domínio de regras nada significam e raramente educam, pois muitas vezes são apenas técnicas que jamais se transformarão em conhecimentos. São ferramentas úteis apenas na hora exata em que são usadas, em nada servindo para o depois. (SELBACH, 2010, p. 22).

$\mathrm{Na}$ perspectiva histórico-cultural a análise dessa compreensão não pode ser feita desligando-se o processo ensino-aprendizagem do seu ambiente social. Os modelos criados pelos alunos podem ser demonstrados pelas suas interpretações, oriundas da via dialógica. A geração de significados para cada situação-problema não pode ser encarada como um produto cognitivo, mas algo que emerge sócio historicamente pela atividade prática. Para Vygotsky (2001), o aprendizado é um processo pelo qual o sujeito, pela interação sociocultural, desenvolve e adquire informações e valores que permanentemente (re)constroem seus saberes prévios.

De acordo com Vygotsky (2001), o campo da psicologia do desenvolvimento cognitivo propicia uma visão diferente na compreensão do processo de desenvolvimento do aluno, permitindo uma (re)organização do processo ensino-aprendizagem com ênfase na qualidade da aprendizagem. Nessa perspectiva, o meio social é o diferencial no processo de desenvolvimento do ser humano. Os signos e a própria linguagem são construções sociais, o conhecimento e os bens materiais são um produto da sociedade, na medida em que a natureza é a matéria-prima, assumindo o indivíduo o

RC: 84456

Disponível em: https://www.nucleodoconhecimento.com.br/comunicacao/marketing-nosdeliverys 
papel de interlocutor no processo de produção desses bens materiais e desse conhecimento.

A aprendizagem matemática ocorre quando for significativa, quando o conteúdo de saber puder ser relacionado às experiências anteriores e vivências pessoais dos alunos. Isto não quer dizer que o sujeito tenha que ter vivido experiências particulares com um determinado conceito ou conteúdo, mas que, essas suas experiências the possibilitem o enfrentamento de novas situações. Assim, permite-se aos alunos a resolução de problemas que de algum modo sejam desafiantes, que estabeleçam diferentes tipos de relações entre fatos, objetos, acontecimentos, noções e conceitos.

Pensamos que falar em aprendizagem significativa consiste em assumir que 0 ato de aprender possui um caráter dinâmico, exigindo ações de ensino que levem os alunos a aprofundar e ampliar os significados elaborados a partir das atividades de aprendizagem. Nessa concepção, o ensino de matemática é um conjunto de atividades sistemáticas, cuidadosamente planejadas, nas quais o professor e o aluno compartilham parcelas de responsabilidade cada vez maiores. O professor guia suas ações para que 0 aluno participe de tarefas e atividades que $o$ aproximem cada vez mais dos conteúdos que a escola tem para lhe ensinar, porém, respeitando seus saberes prévios.

Esta é uma aprendizagem que está relacionada à possibilidade dos alunos aprenderem por múltiplos caminhos, permitindo-Ihes usar diversos meios e modos de expressão. De fato, se analisarmos os princípios da aprendizagem significativa já não parece ter lugar a concepção dominante de inteligência única, que possa ser quantificada e que sirva como padrão de comparação entre pessoas diferentes, para apontar suas desigualdades.

Por isso, a sala de aula torna-se um fórum permanente de debate e negociação de concepções e representações da realidade. Um espaço de conhecimento compartilhado no qual os alunos sejam vistos como sujeitos capazes de construir,

RC: 84456

Disponível em: https://www.nucleodoconhecimento.com.br/comunicacao/marketing-nosdeliverys 
modificar e integrar ideias. Um local de oportunidades para interagir com outras pessoas, com objetos e situações que exijam envolvimento. Uma oportunidade ímpar para pensar e refletir acerca de seus procedimentos, de suas aprendizagens, dos problemas que precisam ser superados.

$\mathrm{Na}$ perspectiva histórico-cultural, um ser humano que vivesse isolado num grupo cultural que desconhece a escrita, por exemplo, jamais a desenvolveria se vivesse apenas nesse contexto. De forma análoga, só vamos entender as atitudes de um aluno a partir do momento que conhecermos seu contexto social. É na prática dialética que modificamos e transformamos a nós mesmos e a realidade circundante. Segundo (OLIVEIRA, 1998, p. 57), o ser humano necessita de "situações próprias ao aprendizado" e "[...] uma criança normal que crescesse num ambiente exclusivamente formado por surdos-mudos não desenvolveria a linguagem oral, mesmo que tivesse todos os requisitos inatos necessários para isso".

Vygotsky (2001) considera que quanto mais o aluno for ajudado, quanto mais rico for o ambiente onde ele estiver inserido, quanto mais instrumentos forem disponibilizados, maiores e melhores serão suas aprendizagens. A percepção da importância desse outro, o social, no desenvolvimento intelectual dos alunos de modo particular e dos seres humanos de modo geral, fez surgir o conceito de zona de desenvolvimento proximal.

\subsection{O SENTIDO DA APRENDIZAGEM MATEMÁTICA ALGÉBRICA NA PERSPECTIVA HISTÓRICO-CULTURAL}

Ensino de matemática fora da realidade do aluno ou que não tenha significado para ele, trará obviamente uma aprendizagem mecânica, portanto,

Persistir no modelo de aulas com alunos sentados em frente a um quadro, copiando de forma mecânica e passiva tudo que o professor escreve, é insistir no mesmo erro que outrora afastou (...) alunos dos estudos (...). Não é que esse tipo de aula deve ser banido por completo (...) ela é necessária, no entanto não pode ser a única ferramenta

RC: 84456

Disponível em: https://www.nucleodoconhecimento.com.br/comunicacao/marketing-nosdeliverys 
utilizada pelos professores. A escola deve ser atrativa e, para isso, o aluno deve ser ouvido. Seus interesses, suas habilidades e seus conhecimentos anteriores devem ser respeitados e utilizados como meio de se atingir a aprendizagem. (ITO, 2016, p. 102).

Diante de propostas metodológicas que ainda insistem no velho modelo de ensino, e que se mostram em partes ineficientes, é que acreditamos no desenvolvimento da capacidade do aluno de pensar, refletir, analisar, compreender conceitos matemáticos, levantar hipóteses, testá-las e validá-las. Neste contexto, acreditamos que os estudos de Vygotsky (2001) podem dar respostas mais interessantes e eficazes para o processo ensino aprendizagem.

Os estudos do autor mostram que a significação da linguagem possibilita o desenvolvimento do pensamento algébrico propiciando este o amadurecimento de uma linguagem matemática simbólica que se torna um instrumento valioso para a resolução de situações de aprendizagem. Ressalta que valorizar o aprendizado cultural no processo de conceitualização, significa reconhecer a importância do papel desempenhado pela linguagem e pelo outro na aprendizagem.

Segundo Vygotsky (2001), isto consolida uma relação de ensino e faz com que os alunos desenvolvam sua forma de pensar e raciocinar junto com os colegas e professores. Segundo (FONTANA, 1996, p. 23), Vygotsky considera "[...] que o aprendizado escolar desempenha papel decisivo no desenvolvimento da elaboração conceitual e na tomada de consciência, pela criança, de seus próprios processos mentais".

O uso de letras em situações de aprendizagem, enfocando problemas distintos, pode propiciar a exploração dos seus vários significados contidos no texto. Dependendo da natureza do problema elas aparecem como valores numéricos, como incógnitas, variáveis ou simplesmente como símbolos abstratos.

Cremos que há a necessidade de se refletir mais dentro do processo ensinoaprendizagem da matemática, em relação à avaliação das questões e ao valor a elas

RC: 84456

Disponível em: https://www.nucleodoconhecimento.com.br/comunicacao/marketing-nosdeliverys 
atribuído, considerando não somente as respostas corretas apresentadas na resolução, mas também a produção do aluno no desenvolvimento das questões. $\mathrm{Na}$ iniciação ao estudo da álgebra no ensino fundamental o importante é desenvolver a capacidade de pensar algebricamente[8]. À medida que o pensamento é constituído pelo aluno, este está em condições, segundo Vygotsky (2001), de trabalhar sozinho ou em grupo na busca do desenvolvimento para chegar a soluções viáveis para as situações-problema propostas.

A linguagem algébrica, como organizadora do pensamento algébrico, possibilitada pelos conceitos, permite aos alunos construir uma forma particular de pensar, extrapolando o contexto matemático, permitindo a reconstituição do próprio pensamento e o desenvolvimento de suas potencialidades.

Sobre resolver situações-problema, (WALLE, 2015, p. 59) menciona:

A resolução de problemas desenvolve nos alunos a conviç̧ão de que eles são capazes de fazer Matemática e de que a Matemática faz sentido. Toda vez que você apresenta uma tarefa baseada em resolução de problemas e aguarda uma solução, você está dizendo aos estudantes "Eu acredito que vocês podem fazer isso". Toda vez que a turma resolve um problema e os alunos desenvolvem sua compreensão, a autoconfiança e a autoestima são ampliadas e fortalecidas (WALLE, 2015, p.59).

De acordo com Vygotsky (2001), trabalhar em pequenos grupos e incentivar o diálogo é salutar para o processo ensino-aprendizagem. Nessa dinâmica, o aluno traz experiências da vida social, conhecimentos cristalizados desde a mais tenra idade, experiências vivenciadas dialeticamente pela interação e integração grupal. $\mathrm{Na}$ interação com o outro o aluno atribui significados informais para as ideias matemáticas e no ensino escolar, de forma intencional, faz-se a sistematização dessas ideias, mediada pelos signos.

A produção de significados para a álgebra, através da realização de diferentes atividades, além de possibilitar uma conexão da álgebra com as matemáticas e outras

RC: 84456

Disponível em: https://www.nucleodoconhecimento.com.br/comunicacao/marketing-nosdeliverys 
áreas do conhecimento, permite o desenvolvimento do pensamento algébrico. Os alunos participam de uma aprendizagem significativa através das relações que se estabelecem na produção de significados de cunho matemático. Pode-se explorar os termos algébricos a partir de um texto em que as ideias são manifestadas na sua origem social. Pela mediação lingüística busca-se construir significados para as palavras, construindo conceitos e uma compreensão coletiva. Em suma, a relação que o ser humano estabelece com o mundo é, nesta perspectiva, uma relação mediada por signos.

Nas palavras de Rego (1998, p. 61), nesta interlocução, "A fala (entendida como instrumento ou signo) tem um papel fundamental de organizadora da atividade prática e das funções psicológicas humanas". O aluno vive e viverá sempre em sociedade, por qual motivo ele teria que aprender algo sozinho? Não seria salutar, dada a nossa realidade social, aprender sempre com ajuda? Estamos de acordo com Vygotsky (2001) quando postula que as atividades realizadas hoje, pelos alunos, com a ajuda de outros sujeitos, poderão estar sendo realizadas individualmente pelos mesmos alunos, no dia de amanhã.

Segundo esta perspectiva, um ensino de álgebra baseado na memorização de fórmulas e resolução individual de exercícios sem justificação não traz entendimento aos alunos e impossibilita uma atuação docente na zona de desenvolvimento proximal da ação educativa. Assim, segundo (VYGOTSKY, 2001, p. 314), didaticamente podase o processo de avançar e aos alunos fica vedado um crescimento em suas potencialidades, pois "[...] a álgebra é mais difícil do que a aritmética para a criança", já que ela exige um maior grau de generalização.

A linguagem matemática, além de universal, é por natureza uma linguagem muito específica. Acredito que isso justifica a necessidade do aluno ter contato com ela através de textos elaborados com o uso natural da linguagem cotidiana, evoluindo nas significações para os conceitos introduzidos. É indispensável para a compreensão da álgebra que o aluno conheça os signos e utilize-os para se apropriar da linguagem e RC: 84456

Disponível em: https://www.nucleodoconhecimento.com.br/comunicacao/marketing-nosdeliverys 
do pensamento algébrico, presentes em todo o ensino da álgebra. Isto poderá melhorar a compreensão e a concepção que os alunos têm da álgebra. Quanto ao professor compete agir como interlocutor deste processo e, pela linguagem, possibilitar ao aluno a compreensão e significação da linguagem algébrica.

Nas atividades algébricas desenvolvidas em sala de aula é comum perceber-se o professor explicando, explicando e o aluno ouvindo, ouvindo. Rompendo-se com essa situação, levando-se os alunos de forma interativa e dialógica a participar das aulas, numa postura de corresponsabilidade, pode-se motivá-los a dar significação aos conceitos algébricos, possibilitando na linguagem significada a aprendizagem discente.

A palavra educação, por si só, já pressupõe nessa dimensão uma relação do indivíduo com a sociedade através de um percurso de desenvolvimento que caminha de fora para dentro, ou seja, do plano social para o individual. O referencial histórico-cultural apresenta também uma maneira de entendermos a relação que se estabelece entre sujeito e objeto no processo de (re)construção do pensamento algébrico.

Nesta perspectiva, o aprendizado só se efetiva pelo desenvolvimento do pensamento via linguagem e com a incorporação de atitudes e valores, construídos em distintas atividades pelo educando, incluindo discussões, leituras, observações e experimentações. Assim, o conhecimento se constrói e se reconstrói pela interação mediada por signos e não se realiza pela observação passiva de conhecimentos. Oliveira (1998, p. 48) destaca que "É no significado que se encontra a unidade das duas funções básicas da linguagem: o intercâmbio social e o pensamento generalizante. São os significados que vão propiciar a mediação simbólica entre o indivíduo e o mundo real [...]".

O conhecimento matemático sistematizado só tem sentido quando interage com a própria matemática e com outros campos do conhecimento. Por isso, faz parte do

RC: 84456

Disponível em: https://www.nucleodoconhecimento.com.br/comunicacao/marketing-nosdeliverys 
trabalho docente a interlocução entre o conhecimento matemático formal e os conhecimentos produzidos nas culturas, os quais o aluno já traz da vivência cotidiana.

Buscar uma aproximação entre o ensinar matemática e o fazer matemática, ensinando conceitos matemáticos a partir de situações atuais e reais, levando em consideração o processo de desenvolvimento do pensamento matemático, é desafio docente. Nesse processo a linguagem permite a internalização dos significados transacionados para os conceitos. O próprio pensamento algébrico é fruto da internalização, ou seja, da significação dos conceitos algébricos.

Assim entendemos que educação é caminhada e de acordo com Freire (1987), ao caminhar o homem se renova sempre e por inteiro: "[...] o novo fica velho se não se renovar" (p. 95). Desta forma e na crença de que sua constituição ocorre dentro de um processo, o trabalho não se conclui, necessita continuamente do confronto com a sala de aula e da discussão permanente com os educadores para renovar-se sempre.

\section{CONSIDERAÇÕES FINAIS}

A linguagem humana, capacidade de comunicação por meio de símbolos precisos, é referida como a condição principal do desenvolvimento cultural e a realização mais elaborada e completa do homem em sua capacidade de operação com signos. Através da aquisição gradual de um sistema simbólico, o homem descobre uma maneira de transformar toda a vida humana. A linguagem, que é parte desse universo simbólico representa uma capacidade exclusiva do ser humano.

O crescimento intelectual depende diretamente do domínio dos mediadores sociais do pensamento, isto é, do domínio das palavras. A linguagem é a ferramenta lingüística do pensamento permitindo que símbolos matemáticos possam ser internalizados pelos alunos quando Ihes significam alguma coisa, possibilitando-lhes, então, lidar com objetos ausentes, levando-os a elaboração de abstrações e generalizações.

RC: 84456

Disponível em: https://www.nucleodoconhecimento.com.br/comunicacao/marketing-nosdeliverys 
$\mathrm{Na}$ reflexão procuramos entender e compartilhar que, na perspectiva de Vygotsky (2001), o professor desempenha um papel fundamental para que ocorra a aprendizagem discente. Para o autor o aprendizado escolar introduz algo novo no desenvolvimento intelectual do aluno, ou seja, ele passa a entender o conhecimento científico e a partir deste compreender o saber cotidiano. Desta forma, aluno e professor, apesar de possuírem entendimentos distintos a respeito de determinada situação, constituem novas aprendizagens ao trocarem entre si informações interativamente.

Para analisar as dimensões do aprendizado da matemática, necessita-se de uma mudança de postura em relação ao papel que o professor desempenha no processo ensino-aprendizagem. Ao professor cabe o papel de propor desafios aos alunos, incentivando-os a desenvolver o raciocínio argumentativo e o estabelecimento de relações pela via dialógica. Sua postura de questionador dá oportunidades de fala a todos, encorajando-os à reflexão sobre o debate, obtendo conclusões do coletivo.

Ensinar matemática na escola, a partir desta perspectiva, implica em atribuir para a aprendizagem importância igual entre o processo de constituição e o apreendido [saber elaborado]. Pressupõe um professor que não mais ensina matérias e sim educa alunos que se organizam sem qualquer pretensão de homogeneidade.

Nesse aspecto, Vygotsky (2001) atribui fundamental relevância ao diálogo que, para ele, permeia todos os momentos da aprendizagem. O fortalecimento do processo ensino-aprendizagem, nesta perspectiva, busca garantir pela mediação lingüística a aprendizagem discente. Os significados são produzidos e apreendidos pelos sujeitos por meio de uma dinâmica interativo-dialógica que procura obter do contexto social os conhecimentos, internalizando-os através de um trabalho realizado pelo professor que dá atenção especial à relação entre a linguagem e o pensamento.

O legado interativo/dialógico aponta para uma ação comunicativa na relação professor-aluno, abre espaço para o debate, a reflexão e a (re)construção do processo

RC: 84456

Disponível em: https://www.nucleodoconhecimento.com.br/comunicacao/marketing-nosdeliverys 
ensino-aprendizagem de matemática. O conhecimento matemático é, nessa dinâmica, obtido da interação realizada entre interlocutores de várias vozes, cuja produção de significados compromete tanto o docente quanto o discente, numa ação pedagógica em que o conhecimento é prenhe de significados construídos históricosocialmente.

Nessa perspectiva, o cotidiano da sala de aula é visto sob um olhar hermenêutico[9], um espaço privilegiado onde o professor é elemento fundamental na interação entre aluno e conhecimento para a efetivação do diálogo entre teoria e prática. Essa dinâmica ressignifica o papel da escola, do professor, do colega, do outro. Cria um espaço privilegiado de acesso à aprendizagem pela via interativo-dialógica.

Acreditamos que a educação matemática pode intervir na formação crítica do cidadão, constituindo sujeitos singularizados. Nesse processo compete ao professor assumir o papel de interlocutor, entre a cultura do aluno e sua aprendizagem. Pela dinâmica interativo-dialógica, cada aprendiz expõe seu ponto de vista e, após as várias falas, ambos constituem um novo entendimento sobre algo a partir de seus saberes prévios.

Cremos que, a realização de um trabalho investigativo nesta perspectiva, ao assumir um caráter intersubjetivo, buscando na linguagem a produção de significados sobre contextos de estudo, contribui para a formação de cidadãos autônomos e reflexivos. Formular conjecturas, oportunizadas por meio de situações-problema contextualizadas, possibilita aos participantes do processo ensino aprendizagem fazer matemática, que é diferente de ter [receber] uma aula de matemática.

Desenvolver em sala de aula uma metodologia de ensino na perspectiva enunciada é por si só um desafio, tanto para a maioria dos professores cuja formação universitária é de cunho tecnicista, quanto para os alunos habituados a um processo ensinoaprendizagem com predominância da concepção platônica.

RC: 84456

Disponível em: https://www.nucleodoconhecimento.com.br/comunicacao/marketing-nosdeliverys 
O presente trabalho não buscou respostas para questões pontuais do ensino de matemática, mas, objetivou fazer uma reflexão sobre possibilidades para o seu ensino. Neste sentido, compartilhamos com Lins (1994), Lins e Gimenez (1997) e Vygotsky (2001), que enfatizam em seus escritos de que é na e pela interação com o outro que o conhecimento aflora no estudante, constituindo-se pela linguagem. Portanto, estas perspectivas abrem possibilidades permanentes para reflexões e aprofundamentos sobre o tema aqui abordado.

\section{REFERÊNCIAS}

DEMO, Pedro. Pesquisa e construção de conhecimento: metodologia científica no caminho de Habermas. 3.ed. Rio de Janeiro: Tempo Brasileiro, 1996. 125 p.

DUARTE JUNIOR, João-Francisco. Por que arte-educação? 7.ed. Campinas: Papirus, 1994. 85 p.

FARIAS, Sandra Alves; BORTOLANZA, Ana Maria Esteves. O papel da linguagem escrita nos processos de ensino e aprendizagem: um estudo teórico. Educação \& Linguagem, v. 18, n. 2, p. 63-85, 2015.

FERREIRA, Edna Cristina. Práticas pedagógicas e objetos de estudo: análise sobre as pesquisas em educação matemática do programa de mestrado da UEPB nos anos de 2007 e 2008. Dissertação (Mestrado) - Universidade Estadual da Paraíba UEPB, Campina Grande, 2013. 383f.

FONTANA, Roseli Aparecida Cação. Mediação pedagógica na sala de aula. Campinas: Autores Associados, 1996. 175 p.

FREIRE, Paulo. A importância do ato de ler: em três artigos que se completam. 18.ed. São Paulo: Autores Associados : Cortez, 1987. 
FREITAS, Maria Teresa de Assunção. Vygotsky e Bakhtin: psicologia e educação: um intertexto. 2.ed. São Paulo, Ática, 1995. 168 p.

ITO, Clayton Meiji. A Matemática para alunos que cumprem medidas socioeducativas em Unidades de Internação do Distrito Federal. 2016.102f.Dissertação de mestrado - Departamento de Matemática. Universidade de Brasília. Distrito Federal.

LINS, R. C.; Gimenez, J. Perspectivas em aritmética e álgebra para o século XXI. Campinas: Papirus, 1997. 176 p.

LINS, Rômulo Campos. Por que discutir teoria do conhecimento é relevante para a Educação Matemática. In: Bicudo, Maria Aparecida Viggiani (Org). Pesquisa em educação matemática: concepções perspectivas. São Paulo: Editora UNESP, 1999, p. $75-94$.

MORAN, J.M. Novas tecnologias e mediação pedagógica [livro eletrônico] /José Manuel Moran, Marcos T. Masetto, Marilda A.B. Campinas, SP: Papirus (2015).

OLIVEIRA, Marta Kohl de. Vygotsky: Aprendizado e desenvolvimento - um processo sócio-histórico. 4.ed. São Paulo: Scipione, 1998. 111 p.

PINHEIRO, R. C.; ROSA, M. Uma perspectiva etnomatemática para o processo de ensino e aprendizagem de alunos Surdos. RPEM, v. 5, n. 9, p. 56-83, 2016.

REGO, Teresa Cristina. Vygotsky: Uma perspectiva histórico-cultural da educação. 5.ed. Petrópolis: Vozes, 1998. 138 p.

SELBACH, S. et al. Matemática e Didática. Petrópolis: Vozes, 2010.

VYGOTSKY, Lev Seminovich. A formação social da mente: o desenvolvimento dos processos psicológicos superiores. 6.ed. São Paulo: Martins Fontes, 1998. $191 \mathrm{p}$.

RC: 84456

Disponível em: https://www.nucleodoconhecimento.com.br/comunicacao/marketing-nosdeliverys 
A construção do pensamento e da linguagem. Trad. De Paulo Bezerra. São Paulo: Martins Fontes, 2001. 496 p.

WALLE, John A. Van de. Matemática no ensino fundamental: formação de professores em sala de aula. $6^{\mathrm{a}}$ ed. Editora Artmed, 2015.

\section{APÊNCIDE - REFERÊNCIA DE NOTA DE RODAPÉ}

7. Entendidas, neste trabalho, segundo a perspectiva de Vygotsky (2001), portanto, construídas de fora para dentro, ou seja, do plano social para o plano individual. Assim, a memória e a atenção, tanto quanto as demais funções superiores, se desenvolvem e evoluem ao longo da história social da humanidade.

8. Entendido como capacidade de desenvolver, pela linguagem significada, um pensamento de caráter generalizante que produza sentido geral sobre determinada situação-problema.

9. Olhar sob o qual há uma compreensão do contexto e uma produção de significados sobre o mesmo, com as justificações correspondentes. Um olhar que concebe, segundo Marques (1993, 2000), o conhecimento como algo (re)construído a várias mãos pelo uso da linguagem.

Enviado: Agosto, 2020.

Aprovado: Maio, 2021.

RC: 84456

Disponível em: https://www.nucleodoconhecimento.com.br/comunicacao/marketing-nosdeliverys 